\title{
The Difference Between Disease and IIIness
}

\author{
Katherine Lach
}

The terms illness and disease are both commonly used to describe deviations from what is considered "normal" in the context of health and medicine. Although these two terms may seem to point to a single, confounded meaning, the distinction between them has long been a source of debate. Indeed, medical historians, anthropologists, sociologists and physicians have not reached a consensus on how these concepts differ or overlap. Nevertheless, it is imperative that physicians have an understanding of how the distinctions are implicated in clinical practice and patient care. This essay explores the history of these concepts as separate entities, the key differences, and how this knowledge is important for physicians' practice.

In modern medicine, "disease" is often seen as an "objective" entity that afflicts all patients equally. In particular, diseases are the entities that have been given names - such as tuberculosis, malaria or diabetes - and are discoverable via some biological, chemical or other markers. This term thus conveniently delineates a "thing" that afflicts the patient from the outside and may be targeted for destruction by medicine. For example, the objective, "disease" aspect of cancer is characterized in all patients by uncontrollable, thus pathological, cell division. By contrast, "illness" refers not to an object, but to a patient's experience of having a disease. This experience of the "illness" is subjective and encompasses all of those aspects of being ill that are unique to individuals: their narratives of their own symptom history, their support network, their attitudes towards being sick, and the duration of the illness, to name just a few components.

The dichotomy between the objective and subjective, and the concept of illness as distinct from that of disease, has its own interesting history.

*To whom correspondence should be addressed:

Katherine Lach

Katherine.lach@mail.mcgill.ca

McGill University
Prior to the "scientific," modern medicine that is the widely accepted disease model of today, illness was seen as a deviation from health caused, not by outside "things" that we now think of as diseases, but by a "violation of natural laws." Violations encompassed a wide range of extrinsic factors that determined health, including the environment, food and drink, lifestyle and mental state - all of which could be seen as the direct cause of what we now know to be infectious disease.4 These "imbalances" were explained in terms of the four humors, which fundamentally held that there was "no such thing as specific diseases." 4 This served as the explanatory model of medicine until the 18th century.4 It was only then that the Western medical tradition began to adopt the "anatomico-clinical method," based upon reasoning from symptoms before death to lesions found upon autopsy. 1 This approach, along with the acceptance of the germ theory of disease, led to the commonly held idea that diseases are "discrete entities - real things."

The idea that diseases assail us from without and thus afflict all patients the same way has not been without usefulness. Indeed, there are biological facts about many diseases, now elucidated, that allow medicine to tackle them with unprecedented success. However, diseases do not act in a vacuum, but act upon individual and unique patients who will experience them differently. Facets of life outside of illness will come to bear upon how it is interpreted and integrated by the patient, including access to health care, economic status and education; this is a facet of sickness that physicians need to pay particular attention to.

Physician and anthropologist Cecil G. Helman has pointed out that lay concepts of disease may affect patients' interpretations of illness. $2 \mathrm{He}$ further outlines a "folk model of illness" that centers upon patients' questions about illness - the "why me's and why now's" - that shape patient behavior.2 The patients' answers to these questions can 
affect how and when they seek medical treatment. For example, patients are more likely to be accepted as truly "ill" by their communities and given care if they are perceived as "blameless," with symptoms that are extrinsically-inflicted, such as from an infection, rather than from lifestyle factors such as smoking or excessive drinking.2

Diseases may or may not produce symptoms; when they do, pain is universally among the most debilitating. Pain is inherently difficult to quantify or treat objectively because, like illness, it relies upon patient narratives to be assessed. One study has shown that patient attitudes towards cancer, or how "catastrophic" it was for them, were directly related to the level of pain that they experienced; similarly, their level of social support influenced their perceptions of pain. Related research made use of the McGill Pain Questionnaire to investigate links between patients' emotional disclosure during doctors' visits and their reported levels of pain. Researchers found that patients who were highly emotional in their narratives had "significantly less pain" and reported higher overall well-being.7 This demonstrates the crucial role of the physician in allowing patients to speak of their own experiences with illness, not merely to allow the "disease" to speak for itself. Our perceptions of our own illness, and of the care that we receive, determine how we experience pain, and to what degree.

Illness brings with it innumerable possibilities of experience; patients may feel any range of emotions, including fear and anxiety, self-pity, and a sense of disconnectedness from their "healthy" peers or communities. Assessing patient emotions is crucial in determining treatment, particularly when considering the patient's role in their own care. For example, managing diabetes mellitus requires lifelong compliance in order to maintain blood glucose homeostasis. This may be particularly difficult, given the role of food and eating as a cultural and social practice - indeed, it has been found that "compliance is often poor in teenage patients who are adversely influenced by peers." In treating this disease, as in all others, physicians need to be aware of how a patient's social setting and peer group influence not just their attitude towards "having a disease," but also, towards compliance with treatment models.

Modern medicine has found myriad ways to diagnose diseases and in many cases, even eliminate their causes. However, how a patient experiences illness cannot be measured in a lab or diagnosed via a physical exam. For this reason, physicians need to pay particular attention to patient narratives of their experiences in order to understand a patient's unique, individual "illness" and thus fully treat their "disease."

\section{REFERENCES}

1. Harrison M. Disease and the Modern World: 1500 to the Present Day. Cambridge: Polity Press; 2004: 1 - 57.

2. Helman CG. Disease Versus Illness in Clinical Practice. J R Coll Gen Pract. 1981; 31 (230): 548 - 552.

3. Mukherjee S. The Emperor of All Maladies: A Biography of Cancer. New York: Scribner; 2010: 16.

4. Waller J. The Discovery of the Germ. Cambridge: Icon; 2002: 10 - 13 .

5. Porter R. The Greatest Benefit to Mankind: A Medical History of Humanity. New York; W. W. Norton \& Company: 313.

6. Zaza C, Baine N. Cancer Pain and Psychosocial Factors: A Critical Review of the Literature. J Pain Symptom Manage. Nov 2002; 24 (5): 526 - 542.

7. Cepeda MS, Chapman RC, Miranda N, Sanchez R, Rodriguez $\mathrm{CH}$, Restrepo AE et al. Emotional Disclosure Through Patient Narrative May Improve Pain and Well-Being: Results of a Randomized Controlled Trial. Jour Pain \& Symptom Management. June 2008; 35 (6): 623 - 631.

8. Kaplan RM, Chadwick MW, Schimmel LE. Social Learning Intervention to Promote Metabolic Control in Type 1 Diabetes Mellitus: Pilot Experiment Results. Diabetes Care. 1985; 8 (2): 152 - 155. 